\title{
Optimal fuzzy-PID controller with derivative filter for load frequency control including UPFC and SMES
}

\author{
Tarakanta Jena, Manoj Kumar Debnath, Smaran Kumar Sanyal
}

Department of Electrical Engineering, Siksha 'O' Anusandhan University, India

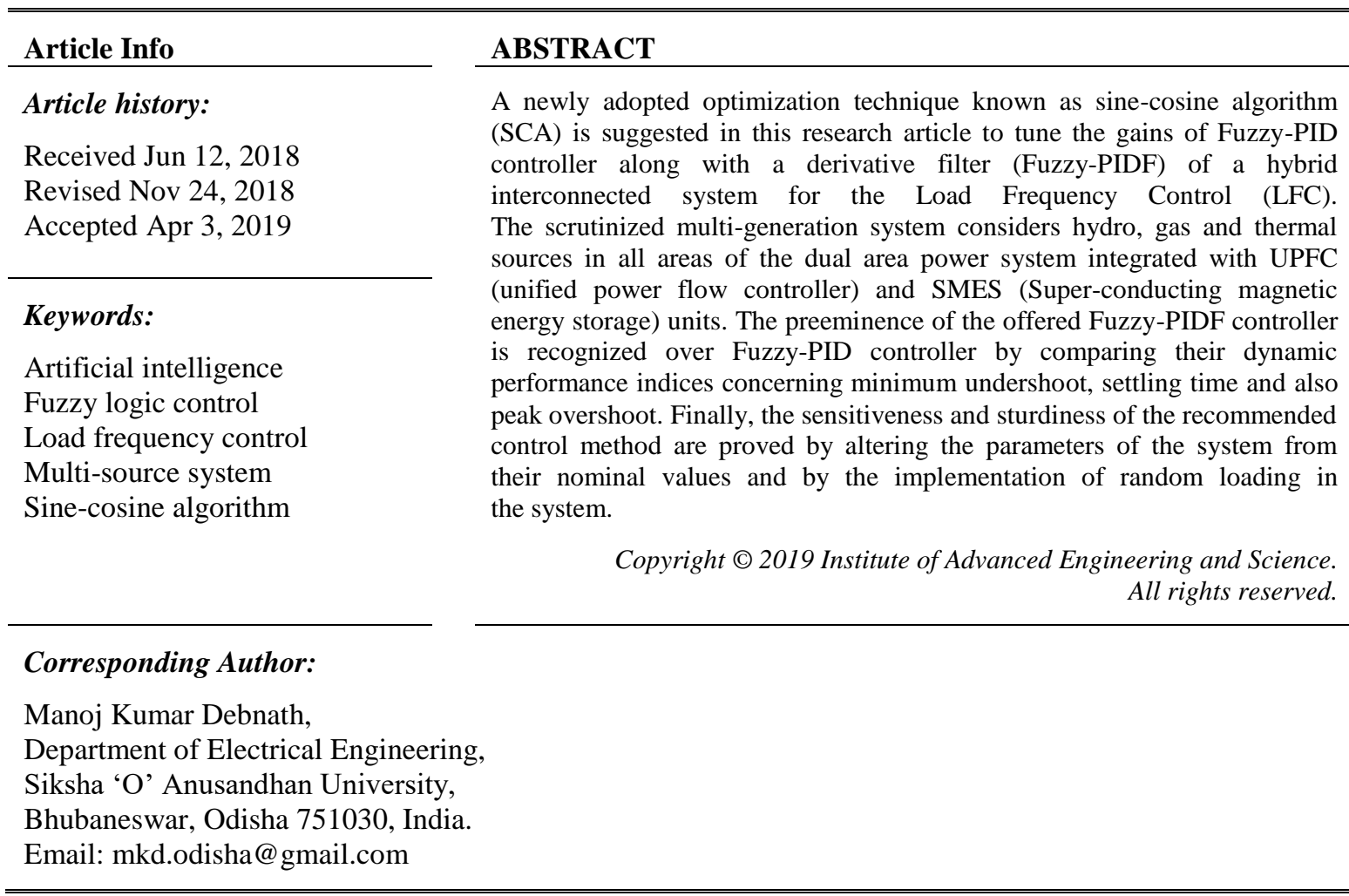

\section{INTRODUCTION}

Being an integral part of modern energy management systems, Automatic generation control has a pivotal responsibility to play in a unified power system. Proper balancing between the aggregate power generation \& the load demands of a particular area ensures the effective and positive operation of an interconnected power system [1]. Subject to a slight deviation of the load demand from normal prescribed values, the system shifts from its stable operating conditions. This shifting from the stable operating point gives rise to deviances in frequency along with tie-line power of interconnected areas. The primary goal of automatic generation control is to preserve frequency of the proposed modelled system within nominal limits. The AGC also makes it sure to ensure the correct exchange of power between interconnected areas.

Extensive literature survey conducted on this field of interest has brought to light several advancements that have been done over the course of time. In 1957, Cohn [2] put forward some theories regarding maintenance of interline power in an interconnected power system. Since then research on AGC has been advancing in a comparatively faster rate. Paper [3] lists down some comprehensive reviews regarding aAutomatic generation control effectively. The use of fuzzy control logic for the gain scheduling of the PID controllers and its use for the AGC control was proposed by Chang et al. [4]. Some recent philosophies related to automatic generation control for interconnected power system was suggested by Kothari et al. [5]. Paper [6] successfully elaborates the hybridization of swarm computation schemes like Particle Swarm Optimization using artificial intelligence like fuzzy logic controller for the tuning of the controller gains of the secondary controllers used in the interconnected power system. Paper [7] considered a hydro-thermal system for inspection as well as analyzed AGC of the system using classical 
controllers. But the use of conventional controllers had the major disadvantage of getting stuck in a single operating point. On subject to change in system conditions, the controller gains needed to be adjusted again. This problem was successfully solved in [8], which clearly elaborates the design of a controller based on artificial intelligence for the AGC of a thermal pus hydro system. Paper [9, 10] deals with the inclusion of various FACTs devices like TCSC, IPFC in the interconnected power system and deals with the AGC studies of the respective systems. Paper [11] also deals with the use of IPFC in the power system and studied the frequency controller of the system. Gains of the controller are tuned utilizing a hybrid pattern searchbiogeographical based optimization technique. The concept of AGC under restructured market systems was successfully explained in [12]. Hybridization of the local-unimodal search \& teaching and learning based optimization method is offered to tune the constraints of PID controller in an interconnected power system for AGC analysis [13]. The first use of newly accepted ant lion optimizing technique for tuning the controller gains of the secondary controllers used in AGC of the interconnected power system was proposed in [14]. The use of 2 DOF PID controller as a secondary controller and its optimization using TLBO technique is recommended in [15]. The study of AGC in a deregulated environment using a neuro-fuzzy technique to optimize controller gains is proposed in [16]. Papers [17, 18] deal with the application of modern optimization technique like edge theorem and differential evolution for the AGC of interconnected power systems. Paper [19] deals with the automatic generation control in an Energy park with the inclusion of a wind farm. In the article [20] hybrid algorithm named as DE-GWO is applied to adjust the fuzzy-based controller parameters of multiple unified systems.

The exhaustive literature survey has put to light that till date all the research works on LFC has been done without the integration of storage devices. This work proposes the Control mechanism to limit the oscillations in the frequency of the hybrid interconnected power system with SMES as an energy storing device along with UPFC as a secondary controller. This work also proposes a Fuzzy-PIDF controller applied to the LFC for the proposed model. The constraints related to Fuzzy-PID/ Fuzzy-PIDF controller structures are optimally tuned using a newly proposed technique for optimization named as Sine-Cos Algorithm. The primary motive of the proposed work is listed below:

a. Designing a multi-sourced system with UPFC and SMES.

b. Tune the parameters of the recommended controller using the sine-cosine algorithm.

c. Comparison of the system performance using Fuzzy-PIDF \& Fuzzy-PID controller implemented in the designed hybrid power system.

Establishment of robustness of the implemented controller by scrutinizing the dynamic performance of the system under parameter variations and load variations.

\section{SYSTEM SCRUTINIZED}

Transfer function structure of the suggested hybrid power system along with UPFC and SMES is depicted in Figure 1. It consists of reheat thermal, hydro as well as gas generating units in each area. Fuzzy-PID controller with derivative filter is suggested for each of the units for the frequency regulation. In this hybrid interconnected power system, different types of parameters are used which are described in the nomenclature section. Here conventional generating sources are used along with SMES in each area. The UPFC and SMES are described in the next section. The deviation in the system is regulated while minimizing the ACE (Area Control error). The ACE presented in each of the areas is expressed as

$$
A C E_{1}=\Delta P_{\text {tiel-2 }}+B_{1} \Delta f_{1} \text { and } A C E_{2}=\Delta P_{\text {tie } 2-1}+B_{2} \Delta f_{2}
$$

where $\Delta P_{\text {tie }}$ is the oscillation of interline power within both the areas, $B_{1}$ as well as $B_{2}$ are frequency bias coefficients of respective areas. $\Delta f_{1}$ along with $\Delta f_{2}$ oscillations of frequency in distinctive area. 


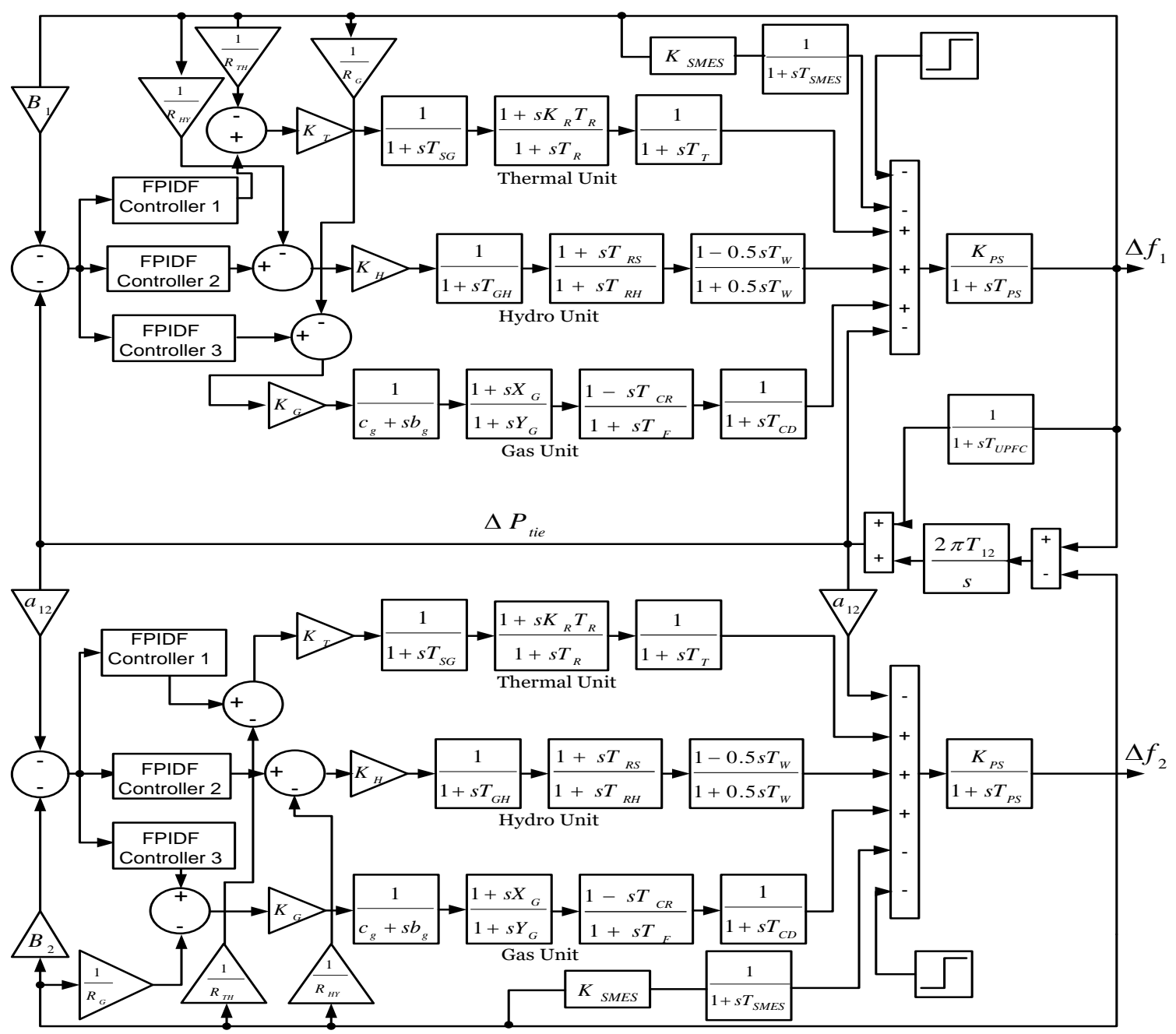

Figure 1. Power system model represented by transfer functions

\subsection{Superconducting magnetic energy storage (SMES)}

Superconducting magnetic energy storage has the capability of storing electricity through the magnetic coil that consists of a superconducting wire near zero loss of energy. It enables to keep and discharge a large amount of power immediately. SMES helps to improve the quality of power by replacing voltage sags and power outages. It plays an imperative role to maintain grid reliability between renewable energy sources and transmission and distribution network. The parts of SMES like ac-dc converter, inverterconverter unit, and a step-down transformer are static in nature and gives better performances as compared to other power storage devices. It also includes superconducting coil and power conditioning system. Inverters or rectifiers are used to transform AC to DC in power conditioning system, and losses about (2-3)\% occurred as compared to other storing energy devices. To improve the power quality, SMES quickly discharge AC power to the grid during an abrupt increase in demand of the load. The superconducting coil is charged to maintain the stability dirung disturbances. The magnetic energy gets stored indefinitely during charging condition. To attain the steady state value, the coil discharges the extra amount of energy to the network. The ability of quick discharge and time delay during charging makes SMES more different among all other energy storage devices. Except that high reliability of supply and less loss of power are the most important advantages of SMES. To maintain the system frequency to its nominal value, SMES are implemented in area-1 as well as in area-2. Perturbation in frequency $(\Delta f)$ along with the variation in the control vector $\left(\triangle P_{S M E S}\right)$ act as input and output of SMES controller respectively. The gains of SMES controller $\left(K_{\text {SMES }}\right)$ and time constant $\left(T_{S M E S}\right)$ has to be optimized. 


\subsection{Unified power flow controller (UPFC)}

Flexible AC transmission system (FACTS) based on power electronics technology helps in improving the quality of transmission by supplying inductive /reactive power to the grid. Unified power flow controller (UPFC) has the capability of suppressing the oscillations in power system to improve transient stability of the power system. Static synchronous compensator (STATCOM) plus static synchronous series compensator (SSSC) are coupled through a general DC voltage link in UPFC. Line reactance, phase angle, and voltage are the controllable parameters of UPFC. $V_{\text {se }}$ and $\Phi_{\text {se }}$ are the series voltage magnitude and the phase angle of series voltage as exposed in the Figure 2 . The real power needed by the series converter is maintained by injecting a suitable amount of shunt voltage by shunt converter. The below expression indicates the complex power at the receiving end of the line.

$$
P_{\text {real }}-j Q_{\text {reactive }}=\bar{V}_{r}^{*}\left\{\frac{\bar{V}_{S}+\bar{V}_{s e}-\bar{V}_{r}}{j(x)}\right\}
$$

Series voltage $V_{s e}$ can be controlled from 0 to $V_{s e \text {, max }}$ and $\phi_{s e}$ can be varied between 0 and 360 degrees at any power angle. The representation of UPFC can be done by

$$
\Delta P_{U P F C}(S)=\left\{\frac{1}{1+S T_{U P F C}}\right\} \Delta F(S)
$$

$T_{U P F C}$ is the time constant of UPFC.

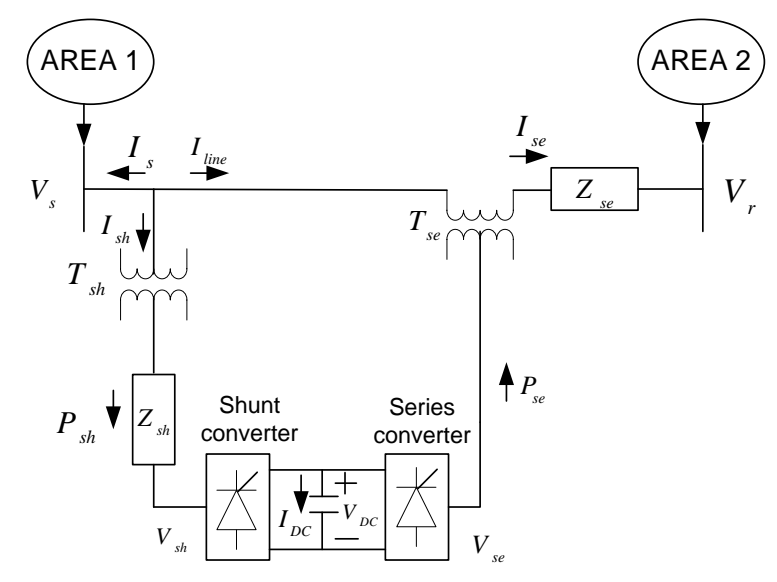

Figure 2. The connection of UPFC in a two area system

\section{PROPOSED TECHNIQUE}

\subsection{Controller structure(fuzzy-PID controller without \& with derivative filter)}

Primarily PID controllers are planned to operate at a specified range of operating condition of the system, and operator manually can adjust the parameters according to the requirement of system. So this classical PID controller is not perfect for time-invariant plants having non-linearity \& time-delay characteristics. So to overcome this problem Zadeh presented fuzzy logic controller based on the conception of computing with words which deals with the imprecision and uncertainties involved in the system. For better frequency regulation in this research article, we injected a derivative filter along with the fuzzy-PID controller. Figure 3 represents the outline of Fuzzy-PIDF controller. Figure 4 represents the five membership functions for input and output variables of Mamdani type fuzzy rule-based fuzzy logic system. The fuzzy rules of the suggested fuzzy controller are depicted in Table 1. Big negative (BN), small negative (SN), Zero (Z), Small positive (SP) \& Big positive (BP) are five linguistic variables used for both input and output of the fuzzy system. Area controller error act as an input to the designed controller for this suggested two area power system shown in Figure 1. ACE is defined as the appropriate linear combination of deviations that occurs in frequency along with tie-line power for a particular area. The Equation (1) represents the ACEs of area1 \& area2 respectively. 


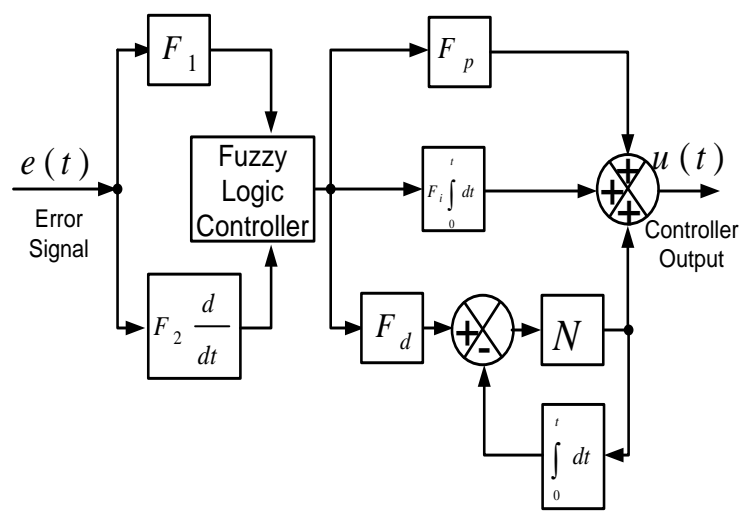

Figure 3. Construction Fuzzy-PID controller with derivative filter

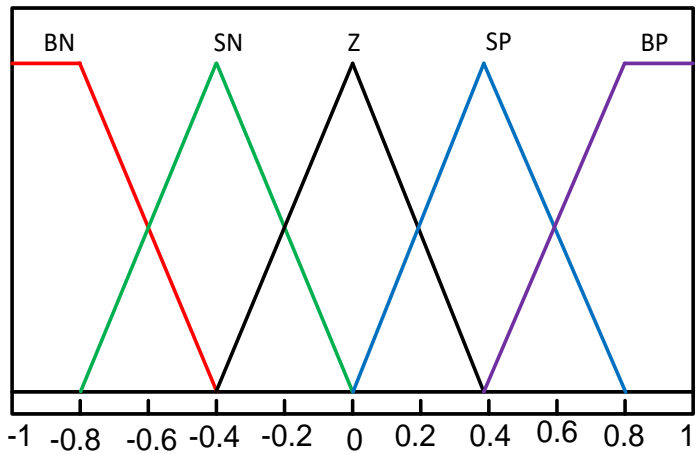

Figure 4. Triangular membership functions for the fuzzy controller

Table 1. Rule base for the fuzzy logic based controller

\begin{tabular}{cccccc}
$\boldsymbol{A C E}$ & \multicolumn{5}{c}{$\boldsymbol{A} \boldsymbol{C E}$} \\
& $\mathrm{BN}$ & $\mathrm{SN}$ & $\mathrm{Z}$ & $\mathrm{SP}$ & $\mathrm{PB}$ \\
\hline $\mathrm{BN}$ & $\mathrm{BN}$ & $\mathrm{BN}$ & $\mathrm{BN}$ & $\mathrm{SN}$ & $\mathrm{Z}$ \\
$\mathrm{SN}$ & $\mathrm{BN}$ & $\mathrm{BN}$ & $\mathrm{SN}$ & $\mathrm{Z}$ & $\mathrm{SP}$ \\
$\mathrm{Z}$ & $\mathrm{BN}$ & $\mathrm{SN}$ & $\mathrm{Z}$ & $\mathrm{SP}$ & $\mathrm{BP}$ \\
$\mathrm{SP}$ & $\mathrm{SN}$ & $\mathrm{Z}$ & $\mathrm{SP}$ & $\mathrm{BP}$ & $\mathrm{BP}$ \\
$\mathrm{BP}$ & $\mathrm{Z}$ & $\mathrm{SP}$ & $\mathrm{BP}$ & $\mathrm{BP}$ & $\mathrm{BP}$ \\
\hline
\end{tabular}

\subsection{Sine cosine algorithm}

On a general note, optimization techniques inspired by population behavior and social aspects start the optimization process with a set of random variables termed as the population. The random population is then weighed with the help of an objective/cost function and is put to improvement based on a set of rules. These rules form the heart of every optimization technique. It is the rules which make one technique different from the other. Since these population-based optimization techniques stochastically search for optimal solutions, it is not always apparent that the very first execution of the optimization program will give the optimal solutions. It might demand a series of repetitive runs to yield optimal solutions. Neglecting the differences between different rules in different optimizers, there is one thing that holds common to all i.e., the partitioning of the entire search process to two halves- exploitation and exploration respectively. In the proposed algorithm the position updation has been done by the following set of formulae.

$$
\begin{aligned}
& X_{i}^{t+1}=X_{i}^{t}+r_{1} \times \sin \left(r_{2}\right) \times\left|r_{3} P_{i}^{t}-X_{i}^{t}\right| \\
& X_{i}^{t+1}=X_{i}^{t}+r_{1} \times \cos \left(r_{2}\right) \times\left|r_{3} P_{i}^{t}-X_{i i}^{t}\right|
\end{aligned}
$$


where $X_{i}$ indicates the current position of the particle in $\mathrm{i}$-th dimension, $\mathrm{r} 1 / \mathrm{r} 2 / \mathrm{r} 3$ stand for the random numbers, $P_{i}$ represents the position of the target point at the ith dimension.

The objective/cost function presented by ITAE is used to tune the scaling factors along with proportional, integral and derivative gains of the fuzzy-PID controller. Terms for the ITAE objective function are outlined in the below equation.

$$
J=I T A E=\int_{0}^{t}\left(\left|\Delta f_{1}\right|+\left|\Delta f_{2}\right|+\left|\Delta P_{t i e}\right|\right) t . d t
$$

\section{RESULTS AND ANALYSIS}

Initially, the transfer function model of two area interconnected power system having multi-source generations with UPFC \& SMES is developed in MATLAB (R2016a) software. To eliminate the steady-state error, the constraints of Fuzzy-PID and Fuzzy-PIDF controller are tuned by sin-cos optimization technique. The design parameters of Fuzzy-PID and Fuzzy-PIDF controllers are taken in the range of [0.01-3.0]. The filter co-efficient ' $\mathrm{N}$ ' has taken in the range of [1-300]. Population size is taken as 100 and as well as the maximum number of iteration is taken as 100. ITAE is used as an objective/cost function to tune gains of the Fuzzy-PID and Fuzzy-PIDF controller which is expressed in Equation (6). In this research paper the system is analyzed under three circumstances namely; (1) A SLP of 0.01 p.u. is applied to area 1; (2) random load perturbation in area 1 and (3) system parameters variations like governor speed regulation (R) and frequency bias parameter $(\mathrm{B})$.

Firstly the system is subjected a step load perturbation of 0.01 p.u. and simulation results for change of frequency in area $1\left(\Delta \mathrm{f}_{1}\right)$ and the change in tie-line power $\left(\Delta \mathrm{P}_{\text {tie }}\right)$ are shown in Figure 5 and Figure 6 respectively. The optimized gains of fuzzy-PID and Fuzzy-PIDF controllers are depicted in Table 2.

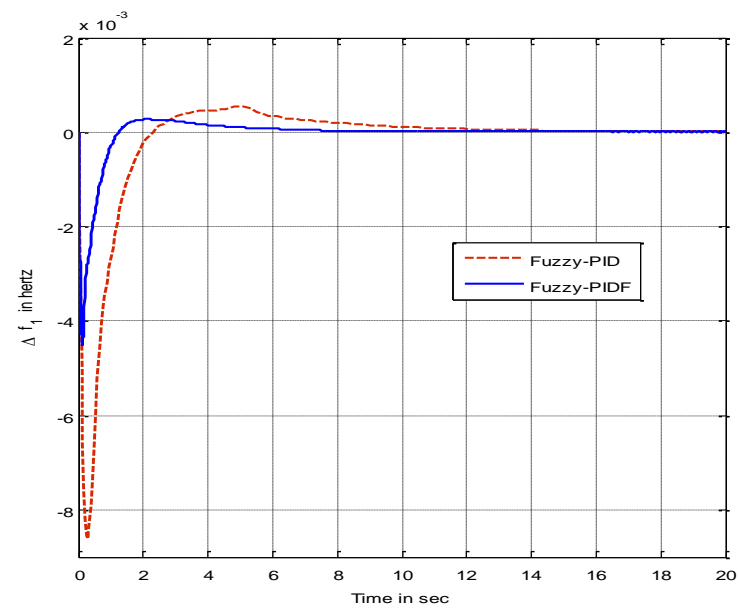

Figure 5. Oscillations of frequency in area 1

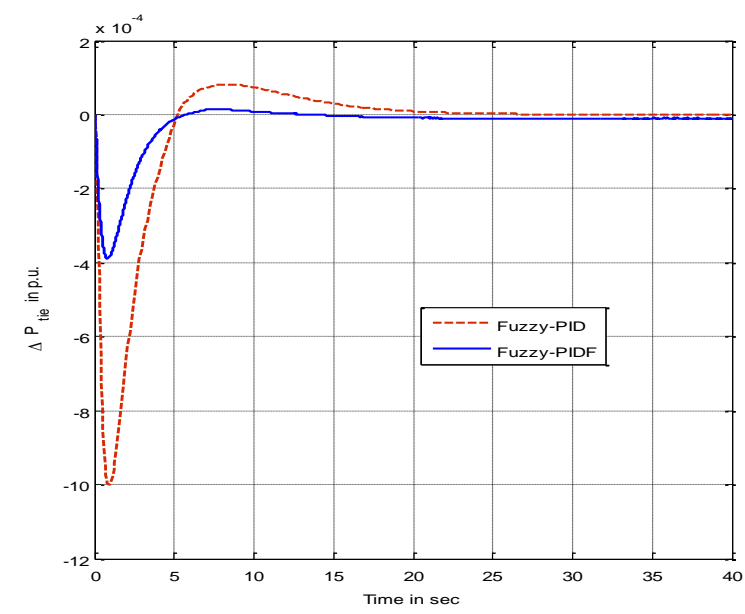

Figure 6. Oscillations of tie-line power

Table 2. The optimized constraints of fuzzy-PID and Fuzzy-PIDF controller tuned by the sin-cos algorithm

\begin{tabular}{ccccccc}
\hline \multirow{2}{*}{$\begin{array}{c}\text { Controller } \\
\text { Parameters }\end{array}$} & \multicolumn{5}{c}{ Sin-Cos algorithm tuned controller } \\
& Thermal & Hyzzy-PIDF & Gas & Thermal & Fuzzy-PID & Hydro \\
\hline$F_{1}$ & 2.8456 & 1.8975 & 1.3578 & 1.8427 & 0.2101 & 1.8754 \\
$F_{2}$ & 2.7854 & 0.1685 & 2.9642 & 1.8978 & 1.0245 & 1.1543 \\
$F_{p}$ & 2.9563 & 0.7523 & 0.8542 & 1.9241 & 0.2131 & 1.8763 \\
$F_{i}$ & 2.3556 & 1.5642 & 1.3542 & 1.6214 & 0.6947 & 1.5879 \\
$F_{d}$ & 2.5134 & 2.3564 & 2.6548 & - & - & - \\
$N$ & 156.2 & 224.5 & 57.8 & - & - & - \\
\hline
\end{tabular}




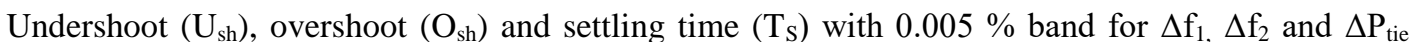
obtained with sin-cos optimization technique for fuzzy-PID and Fuzzy-PIDF controller are shown in Table 3. Critical analysis of dynamic responses from Table 2 and Table 3 reveals that proposed sin-cos optimized fuzzy-PIDF controller holds its supremacy concerning minimum overshoot, undershoot and settling time of $\Delta \mathrm{f}_{1}, \Delta \mathrm{f}_{2} \& \Delta \mathrm{P}_{\text {tie. }}$

Table 3. Time résponse performance indices

\begin{tabular}{ccccccccccc}
\hline & \multicolumn{3}{c}{$\Delta f_{1}$} & \multicolumn{3}{c}{$\Delta f_{2}$} & \multicolumn{3}{c}{$\Delta P_{\text {tie }}$} \\
Controllers & $T_{s}$ & $U_{s h}$ & $O_{s h}$ & $T_{s}$ & $U_{s h}$ & $O_{s h}$ & $T_{s}$ & $U_{s h}$ & $O_{s h}$ \\
& in sec & in & in Hz & in sec & in $\mathrm{Hz}$ & in Hz & in sec & in Hz \\
& & $\left(10^{-3}\right)$ & $\left(10^{-3}\right)$ & & $\left(10^{-3}\right)$ & & $\left(10^{-3}\right)$ & $\left(10^{-3}\right)$ \\
\hline FUZZY-PID & 5.194 & -8.6745 & 0.5491 & 2.889 & -2.99 & 0.209 & 2.29 & -0.955 & 0.0811 \\
FUZZY-PIDF & 0.987 & -3.598 & 0.1998 & 1.31 & -0.69 & 0.009 & 0.798 & -0.29 & 0.0071 \\
\hline
\end{tabular}

In the second case, random loading is subjected to area 1 to study the dynamic performance of this proposed system. It is believed that the controller is treated as efficient if it able to damp out the oscillations quickly which is caused due to the change in loading of the system. The nature of random loading is shown in Figure 7. Figure 8 represent the deviations occur in area $1\left(\Delta f_{1}\right)$ due to random loading respectively. In Fig.8 the response of both Fuzzy-PID and Fuzzy-PIDF are shown simultaneously. From the Figure 8, it can be easily judged that the sin-cos tuned Fuzzy-PIDF controller exhibits superior behavior as comped to the Fuzzy-PID controller.

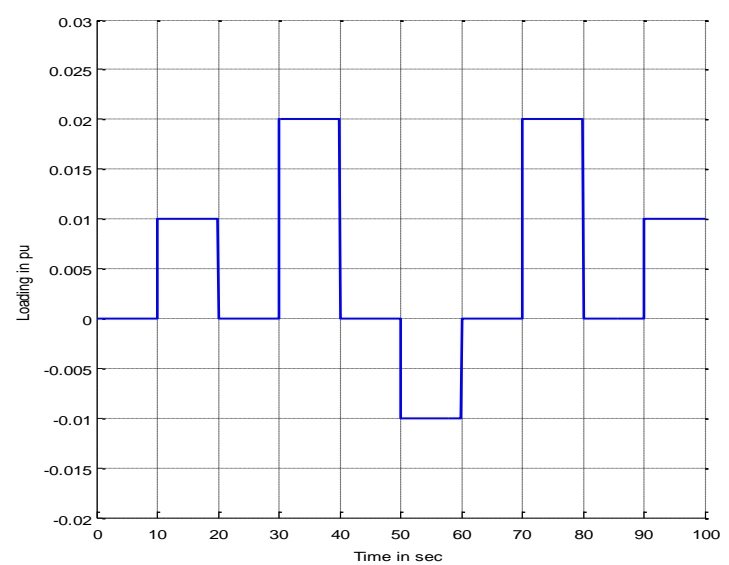

Figure 7. Nature of abnormal loading subjected to area 1

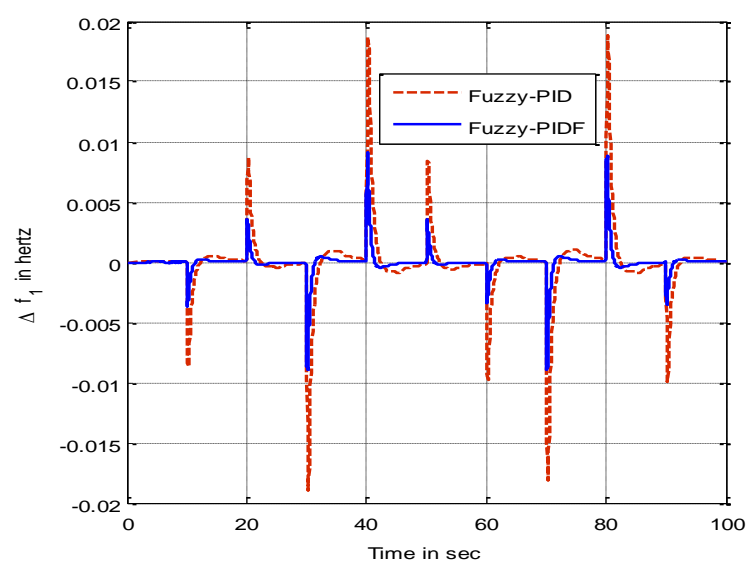

Figure 8. Oscillations of frequency in area 1 due to random disturbance

In the third case the robustness and sensitivity analysis has been carried out to prove the efficiency of sin-cos algorithm tuned Fuzzy-PIDF controller for the scrutinized two-area multi-source system as shown in Figure 1 by varying the parameters of the model like the governor speed regulation parameter $(\mathrm{R})$ and frequency bias parameter (B) from $-50 \%$ to $+50 \%$ in steps of $25 \%$. With the variation of the governor speed regulation parameter $(\mathrm{R})$ as well as frequency bias parameter $(\mathrm{B})$, the response specifications $\left(U_{s h}, O_{s h}\right.$ and $T_{s}$ ) are tabulated as shown in Table 4. From Table 4, it can be commented that the response indices are not varying widely even the system parameters are exposed to a wide range of deviations. Hence, it can be concluded that the system responses with sin-cos tuned suggested Fuzzy-PIDF controller is vital and perform suitably. 
Table 4. Values of the performance parameters for the change in system parameters

\begin{tabular}{|c|c|c|c|c|c|c|c|}
\hline Parameters & $\begin{array}{c}\text { \%age } \\
\text { deviation }\end{array}$ & $\begin{array}{c}U_{s h} \times 10^{-3} \\
\text { for } \Delta f_{1} \\
\quad \text { in } \mathrm{Hz} \text { ) }\end{array}$ & $\begin{array}{c}O_{s h} \times 10^{-3} \\
\text { for } \Delta f_{1} \\
\text { (in } \mathrm{Hz} \text { ) }\end{array}$ & $\begin{array}{c}T_{s} \\
\text { for } \Delta f_{1} \\
\text { (in sec) }\end{array}$ & $\begin{array}{c}U_{s h} \times 10^{-3} \\
\text { for } \Delta f_{2} \\
\quad(\text { in } \mathrm{Hz})\end{array}$ & $\begin{array}{c}O_{s h} \times 10^{-3} \\
\text { for } \Delta f_{2} \\
(\text { in } \mathrm{Hz})\end{array}$ & $\begin{array}{c}T_{s} \\
\text { for } \Delta f_{2} \\
\text { (in sec) }\end{array}$ \\
\hline \multirow{4}{*}{$\mathrm{R}$} & $-50 \%$ & 4.3300 & 0.1066 & -0.0012 & 4.9500 & 0.0802 & -0.0002 \\
\hline & $-25 \%$ & 4.3300 & 0.1067 & -0.0012 & 4.9400 & 0.0804 & -0.0002 \\
\hline & $+25 \%$ & 4.3300 & 0.1069 & -0.0012 & 4.9400 & 0.0806 & -0.0002 \\
\hline & $+50 \%$ & 4.3300 & 0.1070 & -0.0012 & 4.9400 & 0.0807 & -0.0002 \\
\hline \multirow{4}{*}{ B } & $-25 \%$ & 4.5800 & 0.1237 & -0.0014 & 5.1600 & 0.1032 & -0.0003 \\
\hline & $-50 \%$ & 4.4500 & 0.1141 & -0.0013 & 5.0500 & 0.0907 & -0.0002 \\
\hline & $+25 \%$ & 4.2200 & 0.1011 & -0.0011 & 4.8200 & 0.0722 & -0.0002 \\
\hline & $+50 \%$ & 4.1300 & 0.09651 & -0.0010 & 4.7000 & 0.06511 & -0.0002 \\
\hline
\end{tabular}

\section{CONCLUSION}

In this research paper, the Fuzzy-PIDF controller was fruitfully implemented on a hybrid interconnected power system for automatic generation control. Gains of Fuzzy-PIDF controller was accurately tuned by usage of a recently published sin-cos optimization technique. Addition of UPFC and SMES boosted the dynamic performances of the modelled system. To show the robustness of suggested sin-cos algorithm based fuzzy-PIDF controller, the outputs were contrasted with sin-cos based fuzzy-PID controller. A step load perturbation of 0.01 p.u. and a sudden random loading perturbation were subjected to this suggested two area interconnected power system to check its supremacy. Further, a sensitivity analysis has been carried out by varying the governor speed regulation (R) and frequency bias parameter (B). From above analysis, discussion and simulation outputs, it can be concluded that the sin-cos optimized Fuzzy-PIDF controller in AGC system performed well against random loading perturbation and more complex engineering problems as compared to other optimization techniques.

\section{REFERENCES}

[1] P. Kundur, "Power system stability and control," in N. J. Balu and M. G. Lauby, New York, McGraw-hill, vol. 7, 1994

[2] N. Cohn, "Some aspects of tie-line bias control on interconnected power systems," Transactions of the American Institute of Electrical Engineers. Part III: Power Apparatus and Systems, vol/issue: 75(3), pp. 1415-1436, 1956.

[3] P. Kumar, "AGC strategies: A comprehensive review," International journal of power \& energy systems, vol/issue: 16(2), pp. 107-112, 1996

[4] C. S. Chang and W. Fu, "Area load frequency control using fuzzy gain scheduling of PI controllers," Electric Power Systems Research, vol/issue: 42(2), pp. 145-152, 1997.

[5] P. Kumar and D. P. Kothari, "Recent philosophies of automatic generation control strategies in power systems," IEEE transactions on power systems, vol/issue: 20(1), pp. 346-357, 2005.

[6] S. P. Ghoshal, "Optimizations of PID gains by particle swarm optimizations in fuzzy based automatic generation control," Electric Power Systems Research, vol/issue: 72(3), pp. 203-212, 2004.

[7] V. K. Kamboj, et al., "Automatic generation control for interconnected hydro-thermal system with the help of conventional controllers," International Journal of Electrical and Computer Engineering, vol/issue: 2(4), pp. 547, 2012.

[8] C. S. Rao, "Design of artificial intelligent controller for automatic generation control of two area hydrothermal system," International Journal of Electrical and Computer Engineering, vol/issue: 2(2), pp. 183, 2012.

[9] K. Subbaramaiah, "Comparison of performance of SSSC and TCPS in automatic generation control of hydrothermal system under deregulated scenario," International Journal of Electrical and Computer Engineering, vol/issue: 1(1), pp. 21, 2011.

[10] I. A. Chidambaram and B. Paramasivam, "Optimized load-frequency simulation in restructured power system with Redox Flow Batteries and Interline Power Flow Controller," International Journal of Electrical Power \& Energy Systems, vol. 50, pp. 9-24, 2013.

[11] A. Rahman, et al., "Maiden application of hybrid pattern search-biogeography based optimisation technique in automatic generation control of a multi-area system incorporating interline power flow controller," IET Generation, Transmission \& Distribution, vol/issue: 10(7), pp. 1654-1662, 2016.

[12] P. K. Hota and B. Mohanty, "Automatic generation control of multi-source power generation under deregulated environment," International Journal of Electrical Power \& Energy Systems, vol. 75, pp. 205-214, 2016.

[13] B. K. Sahu, et al., "A novel hybrid LUS-TLBO optimized fuzzy-PID controller for load frequency control of multisource power system," International Journal of Electrical Power \& Energy Systems, vol. 74, pp. 58-69, 2016.

[14] M. Raju, et al., "Automatic generation control of a multi-area system using ant lion optimizer algorithm based PID plus second order derivative controller," International Journal of Electrical Power \& Energy Systems, vol. 80, pp. $52-63,2016$

Int J Elec \& Comp Eng, Vol. 9, No. 4, August 2019: 2813 - 2821 
[15] R. K. Sahu, et al., "Teaching learning based optimization algorithm for automatic generation control of power system using 2-DOF PID controller," International Journal of Electrical Power \& Energy Systems, vol. 77, pp. 287-301, 2016.

[16] S. B. Shree and N. Kamaraj, "Hybrid neuro fuzzy approach for automatic generation control in restructured power system," International Journal of Electrical Power \& Energy Systems, vol. 74, pp. 274-285, 2016.

[17] D. Guha, et al., "Study of differential search algorithm based automatic generation control of an interconnected thermal-thermal system with governor dead-band," Applied Soft Computing, vol. 52, pp. 160-175, 2017.

[18] M. Toulabi, et al., "Application of Edge theorem for robust stability analysis of a power system with participating wind power plants in automatic generation control task," IET Renewable Power Generation, 2017.

[19] T. Chakraborty, et al., "Automatic Generation Control using Using an Energy Storage System in a Wind Park," IEEE Transactions on Power Systems, 2017.

[20] M. K. Debnath, et al., "Application of Hybrid Differential Evolution-Grey Wolf Optimization Algorithm for Automatic Generation Control of a Multi-Source Interconnected Power System Using Optimal Fuzzy-PID Controller," Electric Power Components and Systems, vol/issue: 45(19), pp. 2104-2117, 2017.

\section{BIOGRAPHIES OF AUTHORS}

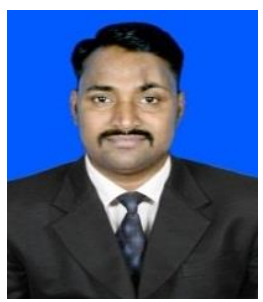

Trarakanta Jena was born in India. He received the B.Tech. degree from Utkal University, Odisha, India in 2001 and M.Tech degree in power electronics drives in 2009 from Siksha 'O' Anusandhan University, Odisha, India. Since 2008, he has been working as an Assistant Professor at Siksha 'O' Anusandhan University, Odisha, India. His research interest includes the application of soft computing in power system control and FACTs.

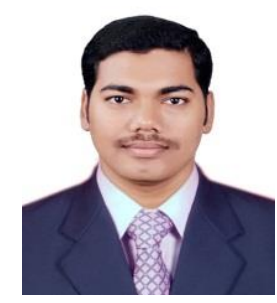

Manoj Kumar Debnath was born in India. He received the B.Tech. degree from Biju Pattnaik University of Technology, Odisha, India in 2007, M.Tech. degree in power system in 2013 and the Ph.D. degree in 2018 from Siksha 'O' Anusandhan University, Odisha, India. Since 2008, he has been working as an Assistant Professor at Siksha 'O' Anusandhan University, Odisha, India. His research interest includes the application of artificial intelligence and soft computing in power system control.

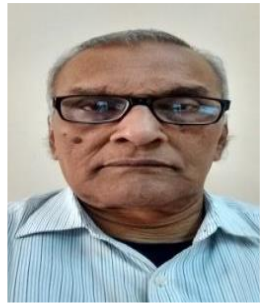

Smaran Kumar Sanyal was born in India. He received his Bachelor's degree in Electrical Engineering from Sambalpur University, Odisha (India) in 1970 and the Master's degree in power system engineering from Sambalpur University, Odisha, India in 1973. He received his Ph.D. from Sambalpur University, Odisha, India in 1980. He is having 42 years of experience in teaching and research. $\mathrm{He}$ is currently working as Professor in the Department of EE, ITER, Siksha 'O' Anusandhan University, Odisha, India. His research interests include Reactive Power Management, Voltage Stability, Power Quality Issues. 